\title{
Dynamical Analysis of Transmission System of Wind Turbine Based on Flexible Supporting
}

\author{
Yufeng Yin ${ }^{1, a}$, Shixiong $\mathrm{Si}^{1, \mathrm{~b}}$, Gaige Jiang ${ }^{1, \mathrm{c}}$ and Yali $\mathrm{Na}^{1, \mathrm{~d}}$ \\ ${ }^{1}$ Department of Mechanical Engineering, Tai Yuan University of Science and Technology, Tai Yuan \\ 030024,China \\ ayinyufeng ty@163.com, ${ }^{\mathrm{b} 1054005811 @ \text { gq.com, }}$ ㄱianggaige@163.com, ${ }^{\mathrm{d} \text { nayali@163.com }}$
}

\begin{abstract}
Keywords: wind turbine; flexible supporting; gearbox; Transmission system; Dynamical Analysis Abstract. With the development of large-scale wind turbine, the flexible deformation produced by the tower under random wind load has an important influence on wind turbine operation life. Considering flexible supporting of the tower for wind turbine and random wind load factors, the gearbox transmission system dynamics coupling model is established for dynamic response analysis. The results show that the axial vibration displacement of gearbox transmission system generated by flexible supporting of the tower is the most important factor when considering dynamics analysis, which laying the foundation for forming a long life, high reliability of the wind turbine design basic theoretical.
\end{abstract}

\section{Introduction}

With the height of the supporting structure in large wind turbine foundation increase, the influence of flexible supporting structure system also increase. As shown in figure 1, under the action of random wind load, elastic deformation of supporting structure, which affects the gearbox transmission system of the turbine to hold,make its internals of coupling movement, makes the system of the dynamic load increases and dynamic response of the system is also changed accordingly[1]. In practice, in the high flexible foundation, under the influence of factors such as the instantaneous load change is extreme, the actual service life of the wind turbine far lower than the other 10 years of design life[2], to show that the traditional rigid support under wind turbine drive system design method and idea on the analysis of system dynamic characteristics and reliability exist shortcomings.

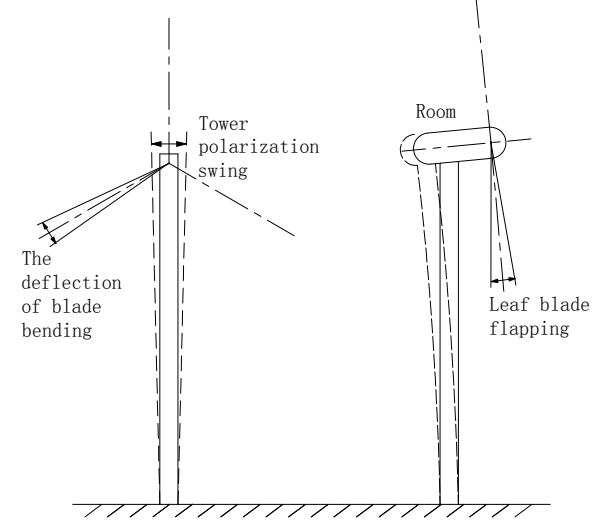

Fig.1 Flexible deformation of tower

\section{The model of wind turbine gearbox transmission system under flexible supporting}

In this paper, the main research object is a $1.5 \mathrm{MW}$ wind turbines with large gearbox gear transmission system. The system consists of NGW planetary transmission system and the secondary parallel shaft helical gear transmission system, including helical gear transmission divided into low speed, medium speed and high speed. Structure diagram as shown in figure 2, the system consists of vane driven spindle, spindle connected planet carrier, planetary gear and planet carrier is fixed, the 
secondary parallel shaft helical gear transmission's torque to the generator rotor blade twist. In figure2, $\mathbf{T}_{\mathbf{I N}}$ means input incentive of the gearbox which equivalent calculated according to the simulation of wind field . Tout $_{\text {oun }}$ means output incentive of the gearbox .Their specific calculation can refer to[1]; Helical gear $i$ can be abbreviated to $G_{i}(i=1,2,3,4)$, ring gear, planet carrier, planet gear $i$ and sun gear can be abbreviated to $G_{A}, P C, G_{p i}, G_{s}$.

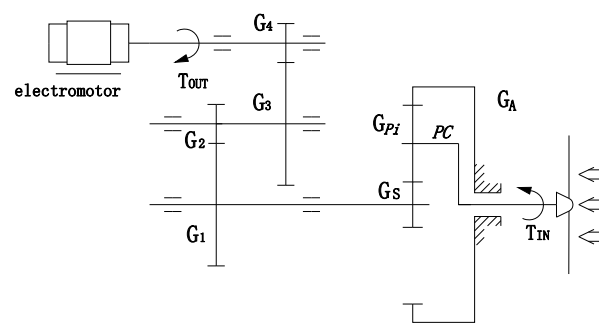

Fig. 2 Schematic of Wind Turbine Drive System

According to the characteristics of the above loading will tower bearing stiffness equivalent to axial, simplifying the time-varying meshing stiffness of gear to spring with time-varying characteristics, based on flexible supporting large-scale wind turbine gearbox transmission tower system more degrees of freedom nonlinear coupling dynamic model, as shown in figure 3 , the complicated stochastic wind load, tower of large-scale wind turbine drive system under the influence of flexible supporting dynamic characteristics is analyzed, and thus more truly reflect the actual running condition of the wind turbine[3].

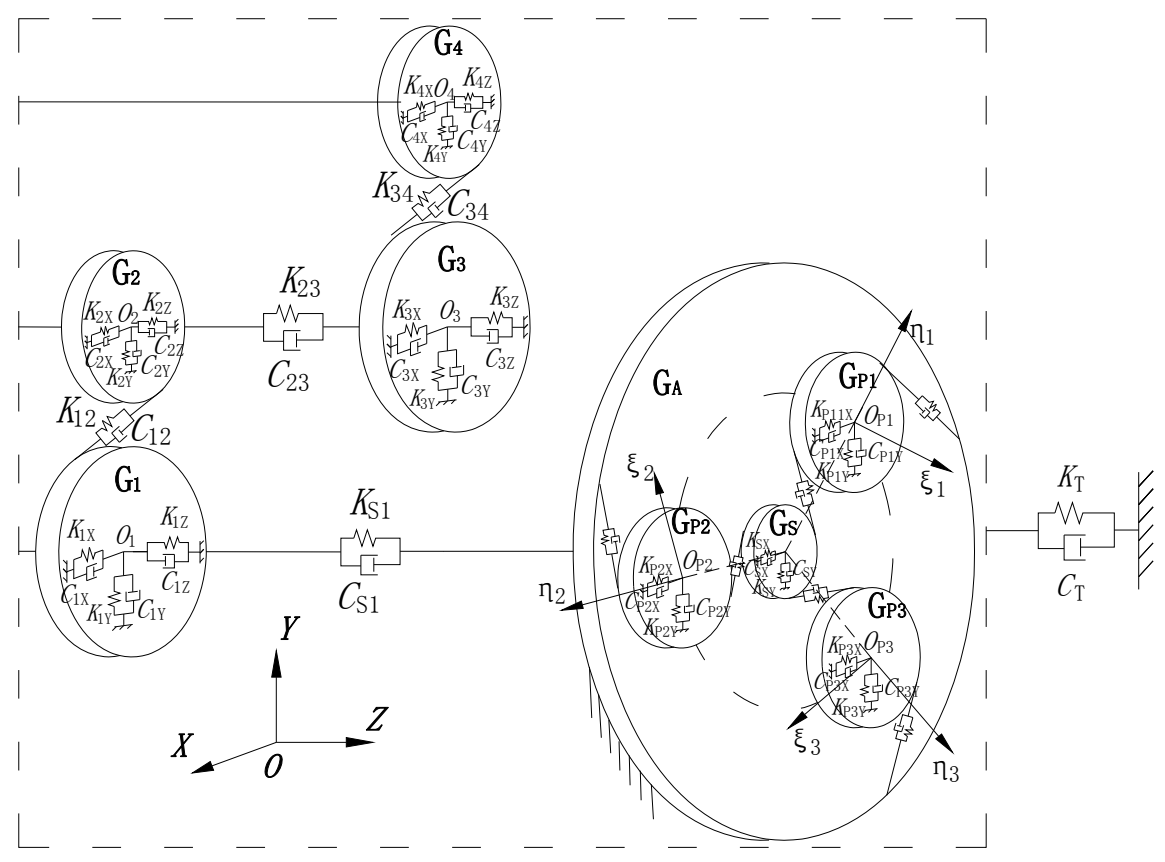

Fig. 3 Coupled model of wind turbine drive system

In figure: Dynamical Model of Helical Gear System

$\mathrm{K}_{\mathrm{PiX}}$ _-stiffness of Planetary gear $\mathrm{G}_{\mathrm{Pi}}$ in the $\mathrm{X}$ direction;

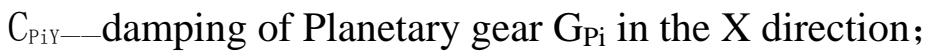

$K_{i x}$ _-stiffness of Helical gear $G_{i}$ in the $X$ direction;

$K_{i Y}$ _-stiffness of Helical gear $G_{i}$ in the $Y$ direction;

$\mathrm{K}_{\mathrm{i} Z}$ _-_tiffness of Helical gear $\mathrm{G}_{\mathrm{i}}$ in the $\mathrm{Z}$ direction;

$\mathrm{C}_{\mathrm{ix}}$ _-damping of Helical gear $\mathrm{G}_{\mathrm{i}}$ in the $\mathrm{X}$ direction;

$\mathrm{C}_{\mathrm{i} Y}$-_damping of Helical gear $\mathrm{G}_{\mathrm{i}}$ in the $\mathrm{Y}$ direction; 
$\mathrm{C}_{\mathrm{i} Z}$ _-_damping of Helical gear $\mathrm{G}_{\mathrm{i}}$ in the $\mathrm{Z}$ direction;

$K_{12}$ _- Helical gear time-varying meshing stiffness between $G_{1}$ and $G_{2}$;

$\mathrm{C}_{12}$ __Helical gear time-varying meshing damping between $\mathrm{G}_{1}$ and $\mathrm{G}_{2}$;

$\mathrm{K}_{34}$-_Helical gear time-varying meshing stiffness between $\mathrm{G}_{3}$ and $\mathrm{G}_{4}$;

$\mathrm{C}_{34}$ _- Helical gear time-varying meshing damping between $\mathrm{G}_{3}$ and $\mathrm{G}_{4}$;

$K_{1 s}$ _- Torsional stiffness of shaft Joining helical gears $G_{1}$ and sun gear $G_{s}$;

$\mathrm{C}_{1 \mathrm{~s}}$-_Torsional damping of shaft Joining helical gears $\mathrm{G}_{1}$ and sun gear $\mathrm{G}_{\mathrm{s}}$;

$\mathrm{K}_{23}$ _- Torsional stiffness of shaft Joining helical gears $\mathrm{G}_{2}$ and helical gear $\mathrm{G}_{3}$;

$\mathrm{C}_{23}$ _- Torsional damping of shaft Joining helical gears $\mathrm{G}_{2}$ and helical gear $\mathrm{G}_{3}$;

$\mathrm{K}_{\mathrm{T}}$ - The bearing stiffness of the tower;

The above parameters can be reference [4].

\section{Wind turbine drive system dynamics equation}

Components according to the transmission system and the relative position relations between loading conditions, can be listed large wind machine under the tower flexible supporting, gear transmission system dynamics equations are as shown in equations(1)-(7):

$$
\left\{\begin{array}{l}
I_{C} \ddot{\theta}_{C}+K_{C} \theta_{C}+\sum_{i=1}^{3} K_{\xi i} X_{P i \xi} r_{C}+C_{C} \dot{\theta}_{C}+\sum_{i=1}^{3} C_{\xi i} X_{P i \xi} r_{C}=T_{I N} \\
m_{C} \ddot{X}_{C}+K_{C X} X_{C}+\sum_{i=1}^{3} K_{\xi i} X_{P i \xi} \cos \varphi_{P i}-\sum_{i=1}^{3} K_{\eta i} X_{P i \eta} \sin \varphi_{P i}+C_{C X} \dot{X}_{C}+\sum_{i=1}^{3} C_{\xi i} X_{P i \xi} \cos \varphi_{P i} \\
-\sum_{i=1}^{3} C_{\eta i} X_{P i \eta} \sin \varphi_{P i}=0 \\
m_{C} \ddot{y}_{C}+K_{C Y} y_{C}+\sum_{i=1}^{3} K_{\xi i} X_{P i \xi} \sin \varphi_{P i}-\sum_{i=1}^{3} K_{\eta i} X_{P i \eta} \cos \varphi_{P i}+C_{C Y} \dot{y}_{C}+\sum_{i=1}^{3} C_{\xi i} X_{P i \xi} \sin \varphi_{P i} \\
-\sum_{i=1}^{3} C_{\eta i} X_{P i \eta} \cos \varphi_{P i}=0
\end{array}\right.
$$

(1) The dynamics equations of planet carrier gear.

$$
\left\{\begin{array}{l}
I_{S} \ddot{\theta}_{S}+K_{1 S}\left(\theta_{S}-\theta_{1}\right)+\sum_{i=1}^{3} K_{S P i} X_{S P i} r_{S}+C_{1 S}\left(\dot{\theta}_{S}-\dot{\theta}_{1}\right)+\sum_{i=1}^{3} C_{S P i} \dot{X}_{S P i} r_{S}=0 \\
m_{S} \ddot{X}_{S}+K_{S X} X_{S}+\sum_{i=1}^{3} K_{S P i} X_{S P i} \cos \varphi_{S P i}+C_{S X} \dot{X}_{S}+\sum_{i=1}^{3} C_{S P i} \dot{X}_{S P i} \cos \varphi_{S P i}=0 \\
m_{S} \ddot{y}_{S}+K_{S Y} y_{S}+\sum_{i=1}^{3} K_{S P i} y_{S P i} \sin \varphi_{S P i}+C_{S Y} \dot{y}_{S}+\sum_{i=1}^{3} C_{S P i} \dot{y}_{S P i} \sin \varphi_{S P i}=0
\end{array}\right.
$$

(2) The dynamics equations of sun gear.

$$
\left\{\begin{array}{l}
I_{P i} \ddot{\theta}_{P i}+K_{P i} \theta_{P i}+\left(K_{P i A} X_{P i A}+C_{P i A} \dot{X}_{P i A}\right) r_{P i}+\left(K_{S P i} X_{S P i}+C_{S P i} \dot{X}_{S P i}\right) r_{P i}+C_{P i} \dot{\theta}_{P i}=0 \\
m_{P i} \ddot{\xi}_{i}+K_{P i \xi} \xi_{i}+K_{S P i} X_{S P i} \sin \alpha_{S P i}+K_{P i A} X_{P i A} \sin \alpha_{P i A}+C_{P i \xi} \dot{\xi}_{i} \\
+C_{S P i} \dot{X}_{S P i} \sin \alpha_{S P i}+C_{P i A} \dot{X}_{P i A} \sin \alpha_{P i A}=0 \\
m_{P i} \ddot{\eta}_{i}+K_{P i \eta} \eta_{i}+K_{S P i} X_{S P i} \cos \alpha_{S P i}+K_{P i A} X_{P i A} \cos \alpha_{P i A}+C_{P i \xi} \dot{\eta}_{i} \\
+C_{S P i} \dot{X}_{S P i} \cos \alpha_{S P i}+C_{P i A} \dot{X}_{P i A} \cos \alpha_{P i A}=0
\end{array}\right.
$$

(3) The dynamics equations of planet gear. 
$\left\{\begin{array}{l}m_{1} \ddot{X}_{1}+K_{1 X} X_{1}-K_{12} X_{12} \cos \beta_{12} \cos \alpha_{12}+C_{1 X} \dot{X}_{1}-C_{12} \dot{X}_{12} \cos \beta_{12} \cos \alpha_{12}=0 \\ m_{1} \ddot{y}_{1}+K_{1 Y} y_{1}-K_{12} \dot{y}_{12} \cos \beta_{12} \sin \alpha_{12}+C_{1 Y} \dot{y}_{1}+C_{12} \dot{y}_{12} \cos \beta_{12} \sin \alpha_{12}=0 \\ m_{1} \ddot{z}_{1}+K_{1 Z} Z_{1}-K_{12} X_{12} \sin \beta_{12}-K_{1 Z} Z_{M 1}+C_{12} \dot{X}_{12} \sin \beta_{12}+C_{1 Z} \dot{Z}_{1}-C_{1 Z} \dot{Z}_{M 1}=0 \\ M_{1} \ddot{z}_{M 1}+\left(K_{T}+K_{1 Z}\right) z_{M 1}-K_{1 Z} Z_{1}+\left(C_{T}+C_{1 Z}\right) \dot{z}_{M 1}-C_{z 1} \dot{z}_{1}=0\end{array}\right.$

(4) The dynamics equations of Helical gear 1.

$\left\{\begin{array}{l}I_{2} \ddot{\theta}_{2}+K_{23}\left(\theta_{2}-\theta_{3}\right)+C_{23}\left(\dot{\theta}_{2}-\dot{\theta}_{3}\right)+\left(K_{12} X_{12}+C_{12} \dot{X}_{12}\right) r_{2} \cos \beta_{12}=0 \\ m_{2} \ddot{X}_{2}+K_{2 X} X_{2}+K_{12} X_{12} \cos \beta_{12} \cos \alpha_{12}+C_{2 X} \dot{X}_{2}+C_{12} \dot{X}_{12} \cos \beta_{12} \cos \alpha_{12}=0 \\ m_{2} \ddot{y}_{2}+K_{2 Y} y_{2}-K_{12} y_{12} \cos \beta_{12} \sin \alpha_{12}+C_{2 Y} \dot{y}_{2}-C_{12} \dot{y}_{12} \cos \beta_{12} \sin \alpha_{12}=0 \\ m_{2} \ddot{Z}_{2}+K_{2 Z} Z_{2}+K_{12} X_{12} \sin \beta_{12}-K_{2 Z} Z_{M 2}+C_{12} \dot{X}_{12} \sin \beta_{12}+C_{2 Z} \dot{Z}_{2}-C_{2 Z} \dot{Z}_{M 2}=0 \\ M_{2} \ddot{Z}_{M 2}+\left(K_{2 Z}-K_{\mathrm{T}}\right) Z_{M 2}-K_{2 Z} Z_{2}+\left(C_{2 Z}-C_{\mathrm{T}}\right) \dot{Z}_{M 2}-C_{2 Z} \dot{Z}_{2}=0\end{array}\right.$

(5) The dynamics equations of Helical gear 2.

$\left\{\begin{array}{l}I_{3} \ddot{\theta}_{3}+K_{23}\left(\theta_{3}-\theta_{2}\right)+C_{23}\left(\dot{\theta}_{3}-\dot{\theta}_{2}\right)-\left(K_{34} X_{34}+C_{34} \dot{X}_{34}\right) r_{3} \cos \beta_{34}=0 \\ m_{3} \ddot{X}_{3}+K_{3 X} X_{3}-K_{34} X_{34} \cos \beta_{34} \cos \alpha_{34}+C_{3 X} \dot{X}_{3}-C_{34} \dot{X}_{34} \cos \beta_{34} \cos \alpha_{34}=0 \\ m_{3} \ddot{y}_{3}+K_{3 Y} y_{3}+K_{34} X_{34} \cos \beta_{34} \sin \alpha_{34}+C_{3 Y} \dot{y}_{3}+C_{34} \dot{X}_{34} \cos \beta_{34} \sin \alpha_{34}=0 \\ m_{3} \ddot{z}_{3}+K_{3 Z} Z_{3}+K_{34} X_{34} \sin \beta_{34}-K_{3 Z} Z_{M 3}+C_{34} \dot{X}_{34} \sin \beta_{34}+C_{3 Z} \dot{z}_{3}-C_{3 Z} \dot{z}_{M 3}=0 \\ M_{3} \ddot{Z}_{M 3}+\left(K_{T}+K_{3 Z}\right) Z_{M 3}-K_{z 3} Z_{3}+\left(C_{T}+C_{3 Z}\right) \dot{z}_{M 3}-C_{z 3} \dot{z}_{3}=0\end{array}\right.$

(6) The dynamics equations of Helical gear 3.

$\left\{\begin{array}{l}I_{4} \ddot{\theta}_{4}+K_{4} \theta_{4}-\left(K_{34} X_{34}+C_{34} \dot{X}_{34}\right) r_{4} \cos \beta_{34}+C_{4} \dot{\theta}_{4}=-T_{\text {out }} \\ m_{4} \ddot{X}_{4}+K_{4 X} X_{4}+K_{34} X_{34} \cos \beta_{34} \cos \alpha_{34}+C_{34} \dot{X}_{34} \cos \beta_{34} \cos \alpha_{34}+C_{4 X} \dot{X}_{4}=0 \\ m_{4} \ddot{y}_{4}+K_{34} X_{34} \cos \beta_{34} \sin \alpha_{34}+K_{4 Y} y_{4}+C_{34} \dot{X}_{34} \cos \beta_{34} \sin \alpha_{34}+C_{4 Y} \dot{y}_{4}=0 \\ m_{4} \ddot{Z}_{4}+K_{4 Z} Z_{4}+K_{34} X_{34} \sin \beta_{34}-K_{4 Z} Z_{M 4}+C_{4 Z} \dot{Z}_{4}+C_{34} \dot{X}_{34} \sin \beta_{34}-C_{4 Z} \dot{Z}_{M 4}=0 \\ M_{4} \ddot{Z}_{M 4}+\left(K_{4 Z}-K_{\mathrm{T}}\right) Z_{M 4}-K_{4 Z} Z_{4}+\left(C_{4 Z}-C_{\mathrm{T}}\right) \dot{Z}_{M 4}-C_{Z 4} \dot{Z}_{4}=0\end{array}\right.$

(7) The dynamics equations of Helical gear 4.

\section{Under the flexible supporting dynamic response analysis of wind turbine drive system}

In this article, the rated power for doubly-fed wind generator speed and blade the features of the gear transmission system dynamics simulation[5]. Wind machine parameters are as follows: the average wind speed of $12 \mathrm{~m} / \mathrm{s}$ wind field and wind turbine design life for 20 years, the impeller speed is 20.83 $\mathrm{r} / \mathrm{min}$, the total transmission ratio is 94.7 , the gear material for 17 crnimo6, 7 is the precision; For Q345E tower adopts cartridge, material, quality of $33.7 \mathrm{t}$. Other related parameters are shown in table $1,2$. 
Tab.1 Parameters of planet gear transmission

\begin{tabular}{|c|c|c|c|c|}
\hline Parameters & $\mathrm{G}_{\mathrm{A}}$ & $\mathrm{G}_{P i}$ & PC & $\mathrm{G}_{\mathrm{S}}$ \\
\hline Weight $(k g)$ & - & 306.11 & 4478.45 & 239.77 \\
\hline Number & 123 & 48 & - & 27 \\
\hline Modulu & \multicolumn{4}{|c|}{12} \\
\hline Angle of engegement $\left({ }^{\circ}\right)$ & \multicolumn{4}{|c|}{22.5} \\
\hline $\begin{array}{l}\text { The average mesh stiffness } \\
\qquad(\mathrm{N} / \mathrm{m})\end{array}$ & \multicolumn{4}{|c|}{$6.05 \times 10^{9}$} \\
\hline Radius of base circle $(\mathrm{mm})$ & 702.67 & 264.25 & 436.11 & 162.15 \\
\hline Rotational inertia $\left(\mathrm{kg} \cdot \mathrm{m}^{2}\right)$ & - & 9.92 & 1024.3 & 4.24 \\
\hline
\end{tabular}

Tab.2 Parameters of helical gear transmission

\begin{tabular}{|c|c|c|c|c|}
\hline Parameters & $\mathrm{G}_{1}$ & $\mathrm{G}_{2}$ & $\mathrm{G}_{3}$ & $\mathrm{G}_{4}$ \\
\hline weight $(\mathrm{kg})$ & 1096 & 101.7 & 189.5 & 25.9 \\
\hline Number & 104 & 23 & 98 & 25 \\
\hline Modulu & \multicolumn{4}{|c|}{6.5} \\
\hline Angle of engegement( ${ }^{\circ}$ ) & \multicolumn{4}{|c|}{20} \\
\hline $\begin{array}{l}\text { The average mesh stiffness } \\
\qquad(\mathrm{N} / \mathrm{m})\end{array}$ & \multicolumn{4}{|c|}{$3.25 \times 10^{9}$} \\
\hline radius of base circle $(\mathrm{mm})$ & 487.5 & 107.8 & 305.7 & 77.9 \\
\hline rotational inertia $\left(\mathrm{kg} \cdot \mathrm{m}^{2}\right)$ & 152.16 & 0.69 & 8.5 & 0.07 \\
\hline
\end{tabular}

According to the method of combination wind speed system input torque for 600 seconds before the time process curve as shown in figure 4.

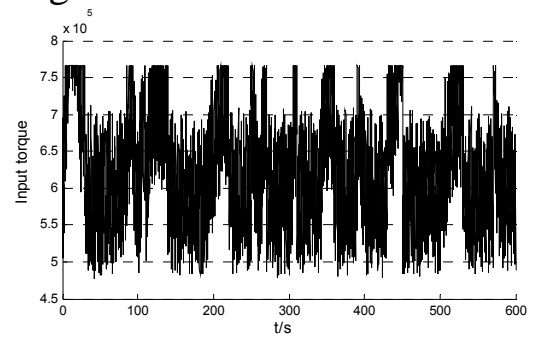

Fig.4 System input torque in first 20s

By solving the dynamic equation of large-scale wind turbine gearbox transmission system in the tower, under the influence of factors such as flexible supporting parts in translation direction and reverse direction vibration response, as shown in figure 5 . In the chart of negative said the parts with mechanical model for vibration displacement direction set coordinates are in the opposite direction.

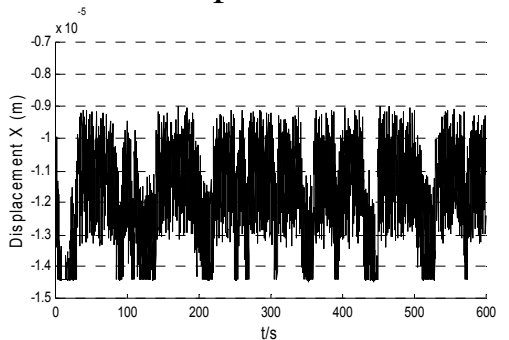

(a)

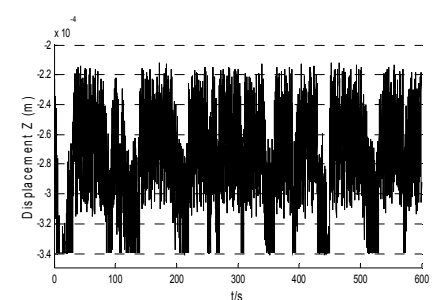

(b) 


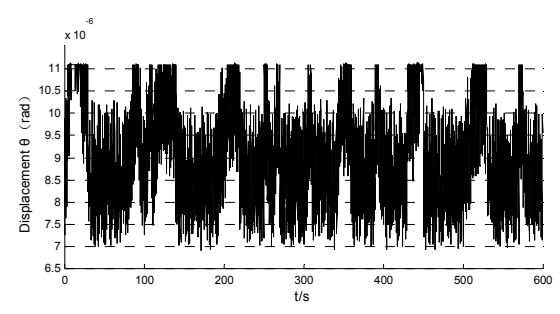

(c)

Fig.5 Vibration displacement of each component

We can know from figure 5, the planet carrier PCS wheel $G_{S}$ in the $x$ direction translation with the sun on the vibration displacement amplitude is small, this is due to random wind load is the main external incentives, wind turbine drive system via the blade rotation to the gearbox transmission system, is a kind of torque, small influence on the response of the direction of translation. Flexible supporting makes the tower of wind turbine gear box parallel shaft gear train components to produce the axial secondary namely the $\mathrm{z}$ direction of the coupling movement. Helical gears $\mathrm{G}_{1}$ is from the sun wheel torque of $G_{S}$ and helical gear meshing force of $G_{2}$, at the same time due to the flexible supporting tower, coupling movement in $\mathrm{Z}$ direction, produce axial displacement, other helical gear is similar to the $G_{1}$.

\section{Conclusions}

In this paper, based on the flexible supporting large-scale wind turbine gearbox transmission system dynamics equation, on the basis of the equation is solved by numerical simulation, it is concluded that the vibration displacement response of members of the drive system, the analysis shows that the transmission system by the influence of flexible supporting tower, secondary parallel shaft helical gear axial displacement, vibration response of the nonlinear characteristics is also more complex, the obvious. The results of wind turbine reliability design, the research content has a certain reference value.

\section{Acknowledgements}

This work was financially supported by the Research Project Supported by Shanxi Scholarship Council of China (2014-063) and Graduate Innovation Program of Taiyuan University of Science and Technology (20145031).

\section{References}

[1] Yin YuFeng, Ding JianGang and Li YongJian: Trans Tech Publications, 2014. 249-255. (In Chinese)

[2] Shing T K, Tsai L W, Krishnaprasad P S. Dynamic model of a spur geared system with backlash and friction consideration[C]. ASME Proc Machine Elements and Machine Dynamics Conf, DE71, 1994. 155-163.

[3] Velex P, Cahouet V. ASME Mech Des, 2000, 122:515-522.

[4]Li Rui Fang, Wang Jian Jun: Dynamics of gear system [M]. Science Press,Beijing,1997.(In Chinese)

[5] Chen Hui-tao. Stochastic vibration analysis of gear transmission system of wind turbine and probabilistic optimization design based on dynamic reliability [D]. Chongqing: Chongqing University, 2012. (In Chinese) 